\title{
A Comparative Study of the Changes in the Morphology of Hyphae during Freezing and Viability upon Thawing for Twenty Species of Fungi
}

\author{
By G. J. MORRIS, ${ }^{1 *}$ D. SMITH ${ }^{2}$ AND G. E. COULSON ${ }^{1}$ \\ ${ }^{1}$ Cell Systems Ltd, Cambridge Science Park, Milton Road, Cambridge CB4 4FY, UK \\ ${ }^{2} C A B$ International Mycological Institute, Ferry Lane, Kew, Surrey TW9 3AF, UK
}

(Received 24 March 1988; revised 7 July 1988)

\begin{abstract}
The changes in morphology and viability of 20 species of fungi during freezing were examined in relation to cooling rate and the presence of glycerol. All of the hyphomycetes examined, the ascomycete Sordaria, the zygomycete Mucor, and the basidiomycete Schizophyllum, survived freezing and thawing in the absence of glycerol. Cryomicroscopy demonstrated that for these fungi the formation of intracellular ice at rapid rates of cooling was not lethal. Isolates from the oomycetes and some basidiomycetes required glycerol for survival. The morphological response of Phytophthora, Aschersonia and Volvariella differed from other genera, with shrinkage occurring at all rates of cooling. The conventionally employed cooling rate for the cryopreservation of fungi, $1{ }^{\circ} \mathrm{C} \mathrm{min}-1$, was found not to be optimal for all of the strains studied. Serpula recovered best after cooling at $0.5{ }^{\circ} \mathrm{C} \mathrm{min}{ }^{-1}$ followed by rapid thawing, and all the oomycetes examined gave highest recovery after cooling at rates between 5 and $10^{\circ} \mathrm{C} \mathrm{min}{ }^{-1}$ followed by rapid thawing.
\end{abstract}

\section{INTRODUCTION}

The cryopreservation of filamentous fungi in liquid nitrogen has been widely employed since reported by Hwang (1960). The methods used initially were not developed for fungi, but were those derived empirically for avian spermatozoa (Polge et al., 1949). Despite the early success of the method, many strains of fungi fail to survive, particularly isolates of the Mastigomycotina and Basidiomycotina. The ultrastructural effects of rapid rates of cooling used in freeze-fixation have been reviewed (Hoch, 1986). However, to enable the improvement of the cryopreservation technique it has become necessary to determine the dynamic effects of freezing and thawing on the fungal cell.

When freezing is initiated in an aqueous solution only a proportion of the water undergoes transition to ice and the solutes in the residual aqueous solution become more concentrated. Cells in suspension are exposed to hypertonic solutions during freezing and cellular morphology is generally determined by the rate of cooling. With fungi, two responses have been reported (Coulson et al., 1986; Smith et al., 1986). In Penicillium expansum, dehydration of hyphae was observed at rates of cooling of less than $15^{\circ} \mathrm{C} \mathrm{min}-1$; at cooling rates greater than $50^{\circ} \mathrm{C} \mathrm{min}{ }^{-1}$ intracellular ice formed in all hyphae. By contrast, with Phytophthora nicotianae, shrinkage was observed at all rates of cooling examined $\left(10-120^{\circ} \mathrm{C} \mathrm{min}^{-1}\right)$; intracellular ice formation did not occur. In this study we extend these observations to a wider range of fungal species. In addition, the effect of various concentrations and types of cryoprotective additives on the morphological response of Penicillium expansum was examined. The viability of cultures following cooling at different rates to $-196^{\circ} \mathrm{C}$ was determined in the presence or absence of glycerol, allowing the relationship between morphology during freezing and viability upon thawing to be critically examined. The fungi were thawed rapidly (approx. $200^{\circ} \mathrm{C} \mathrm{min}-1$ ) as this was shown to give the highest recovery for Penicillium expansum (Smith et al., 1986). 

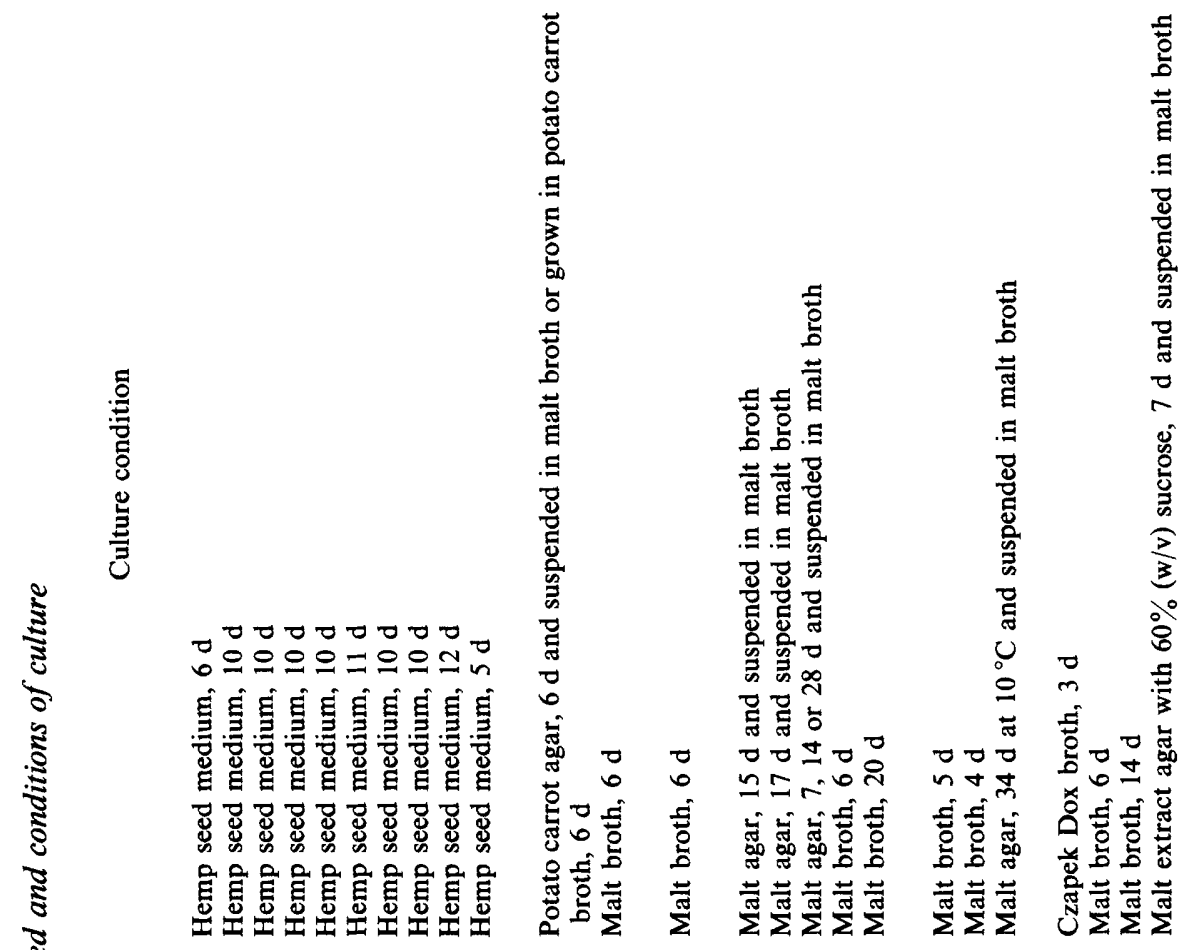

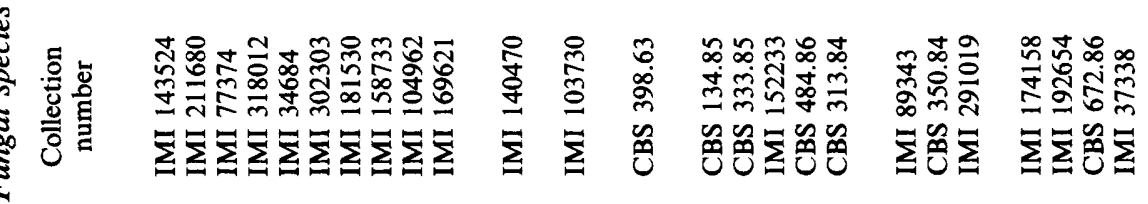

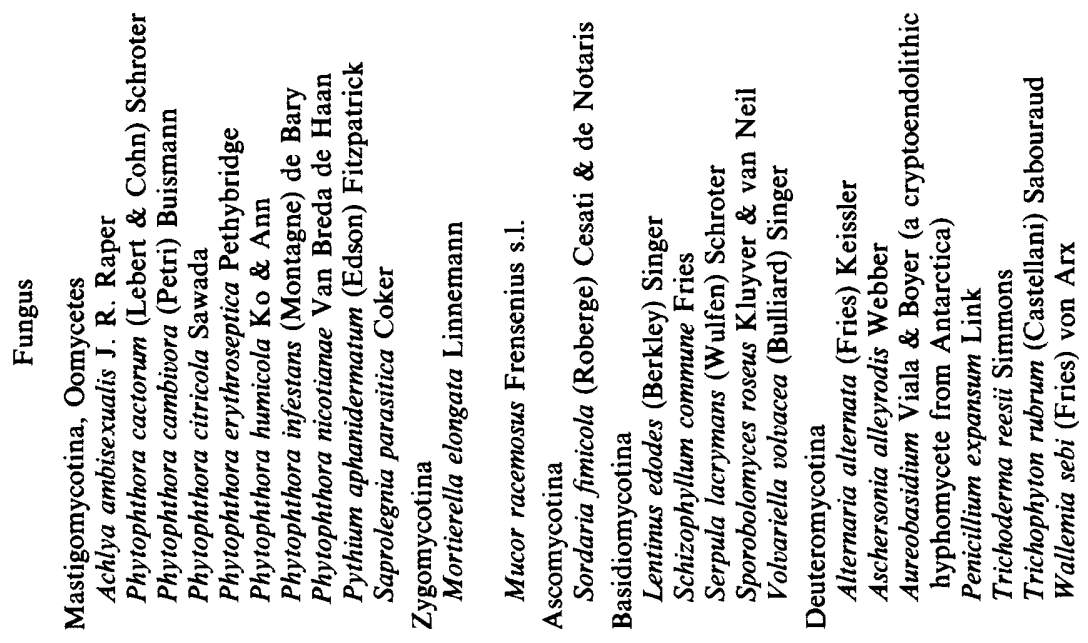




\section{METHODS}

Preparation of fungal cultures. The fungi were grown on suitable solid agar media (Smith \& Onions, 1983) and either conidia or agar blocks cut from the edge of the colonies were inoculated into appropriate medium. The strains were obtained either from the CAB International Mycological Institute (IMI) or from the Centraalbureau voor Schimmelcultures (CBS), and incubated at $20^{\circ} \mathrm{C}$ unless otherwise stated; other conditions of culture are listed in Table 1.

During incubation the broth cultures were agitated occasionally to break up the colonies. The different growth periods for each genus were chosen in order to obtain non-sporulating cultures in the form of small, thin and detached mycelial mats. To avoid mechanical damage intact colonies $0.5-1.0 \mathrm{~mm}$ in diameter were selected for observation and transferred from the broth cultures to the stage of the cryomicroscope with an Eppendorf multipipette. At least three replicates were prepared for each cooling rate.

Cooling at different rates to $-196^{\circ} \mathrm{C}$. Colonies were placed in $0.5 \mathrm{ml}$ volumes of either growth medium, as described above, or glycerol $(10 \%, \mathrm{v} / \mathrm{v}$, in distilled water) in $1.5 \mathrm{ml}(12.5 \times 44 \mathrm{~mm})$ sterile polypropylene cryogenic vials. Colonies in growth medium were frozen without further incubation, those in glycerol were equilibrated at approximately $20^{\circ} \mathrm{C}$ for $1 \mathrm{~h}$. The tubes were cooled at different rates by placing them on the shelf of a freeze-drier (Edwards High Vacuum Minifast 3400) for the rate of $1{ }^{\circ} \mathrm{C} \mathrm{min}{ }^{-1}$, or in a temperature controlled refrigerated bath (Fryka-Therm FT 800) for rates between 5 and $15^{\circ} \mathrm{C}$, in the vapour of liquid nitrogen for rates between 20 and $50{ }^{\circ} \mathrm{C} \mathrm{min}-1$ or plunged directly into liquid nitrogen. All tubes were then cooled rapidly to $-196{ }^{\circ} \mathrm{C}$ in liquid nitrogen. The rate of cooling, determined from the time required to cool between ambient and $-40^{\circ} \mathrm{C}$, was measured from a replicate sample using a copper-constantan thermocouple connected to a Type 767T digital panel thermometer linked to an Omniscribe D-500 strip chart recorder. The hyphae were thawed after $5 \mathrm{~min}$ at $-196^{\circ} \mathrm{C}$ by rapid agitation of the tube in a water bath at $35^{\circ} \mathrm{C}$ until the last crystals of ice had melted. There were four replicates for each cooling rate and counts were done in duplicate.

Assay of viability. Regrowth was determined by transferring colonies of the fungi to the agar growth medium indicated in Table 1. Colonies were scored between 36 and $72 \mathrm{~h}$ depending on the growth rate of the fungus.

Cryomicroscopy. During freezing, hyphae were observed on a cryomicroscope conduction stage (McGrath, 1987); a microcomputer (IBM PC) was used for temperature control of the stage heater. They were cooled from 20 to $5^{\circ} \mathrm{C}$ at a rate of $10^{\circ} \mathrm{C} \mathrm{min}^{-1}$, held at $5{ }^{\circ} \mathrm{C}$ for $0.5 \mathrm{~min}$, and then cooled at different linear rates to $-50^{\circ} \mathrm{C}$. Three replicates or more were observed for each cooling rate and a total of at least 25 hyphae were examined from each species.

The conduction stage was mounted onto a Leitz Diaplan microscope fitted with a $40 / 0.7$ objective combined with a $2 \times$ magnification changer. Data were recorded on video (Hitachi HV-65 camera, Sony U-matic recorder model VO-5630) using a video character generator (ForA Electronics model VC-81). The recorded data were played back for analysis on a video monitor (Hitachi model VM-906a).

\section{RESULTS}

\section{Cryomicroscopy}

The fungi could be divided into two groups on the basis of their morphological response to freezing. In the majority of ascomycete, hyphomycete and oomycete species examined, shrinkage occurred at low rates of cooling, while at faster rates less shrinkage was evident and intracellular ice formed. These morphological responses are illustrated here with Saprolegnia parasitica (Fig. 1). During cooling at $2{ }^{\circ} \mathrm{C} \mathrm{min}-1$ extensive shrinkage of the hyphae occurred but there was no observable separation of the protoplast from the cell wall. Upon thawing, the filaments re-expanded to their unfrozen dimensions with no immediate lysis. At $20^{\circ} \mathrm{C} \mathrm{min}^{-1}$ generally no shrinkage of hyphae occurred and hyphae became granular throughout (Fig. 1 h). Rarely, intracellular ice nucleated in some portions of the filament with the adjacent sections shrinking or collapsing (Fig. 1i).

To allow comparison of different species, the rate of cooling at which $50 \%$ of hyphae formed intracellular ice was determined graphically; in the cases of the isolates in Fig. 2(a), these were at $4 \cdot 5,5 \cdot 8,15$ and $53{ }^{\circ} \mathrm{C} \mathrm{min}-1$, respectively. Data on other species are presented in Table 2.

In contrast, some species (Aschersonia alleyrodis, Phytophthora nicotianae and Volvariella volvacea) shrank at all rates of cooling examined $\left(10-100^{\circ} \mathrm{C} \mathrm{min}^{-1}\right)$ and intracellular ice was not observed. To further examine the response of Phytophthora, five other species were observed at rapid rates of cooling. Intracellular ice was not seen at any rate of cooling examined in $P$. cambivora and $P$. citricola; with $P$. erythroseptica and $P$. infestans intracellular ice was 

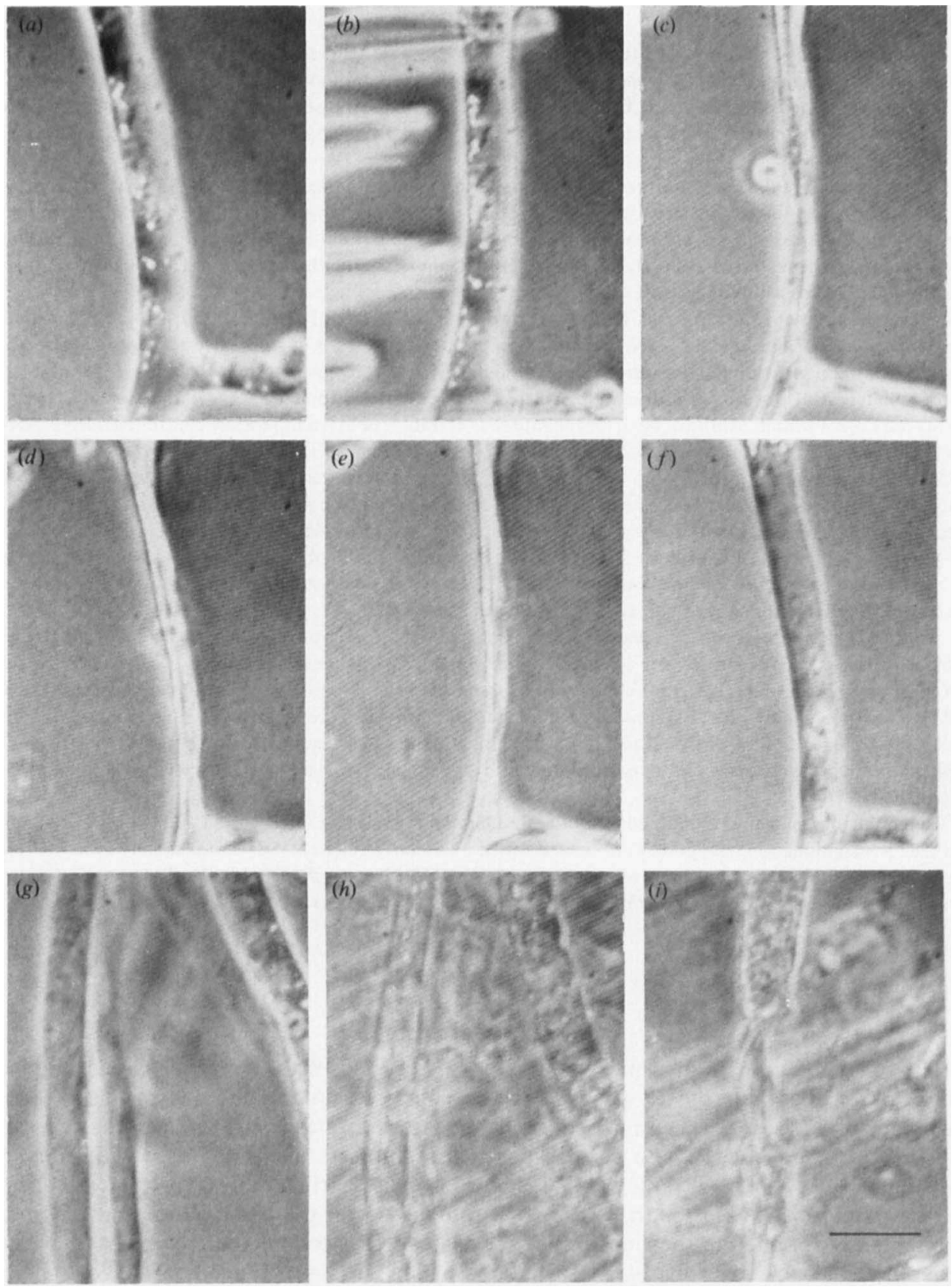

Fig. 1. Light microscopy of Saprolegnia parasitica during cooling at rates of $2{ }^{\circ} \mathrm{C} \mathrm{min}-1(a-f)$ and $20^{\circ} \mathrm{C}$ $\min ^{-1}(g-i)$. (a) Unfrozen control, $(b)$ ice front, $(c)-5^{\circ} \mathrm{C},(d)-10^{\circ} \mathrm{C},(e)-30^{\circ} \mathrm{C},(f)$ upon thawing. (g) Unfrozen control; $(h, i)-30^{\circ} \mathrm{C}$. Bar, $10 \mu \mathrm{m}$.

observed at $50^{\circ} \mathrm{C} \mathrm{min}-1$ but not at $30^{\circ} \mathrm{C} \mathrm{min}-1$, whilst in $P$. cactorum intracellular ice was observed at 100 but not at $50{ }^{\circ} \mathrm{C} \mathrm{min}{ }^{-1}$. With three species, Sporobolomyces roseus, Lentinus edodes and Aureobasidium sp., intracellular ice formation was not observed even at rates of $100{ }^{\circ} \mathrm{C} \mathrm{min}-1$. However, in these cases extensive shrinkage was not observed and it is possible that failure to see intracellular ice was a limitation of light microscopy optics.

The nucleation temperature for intracellular ice formation and its relation to the rate of 

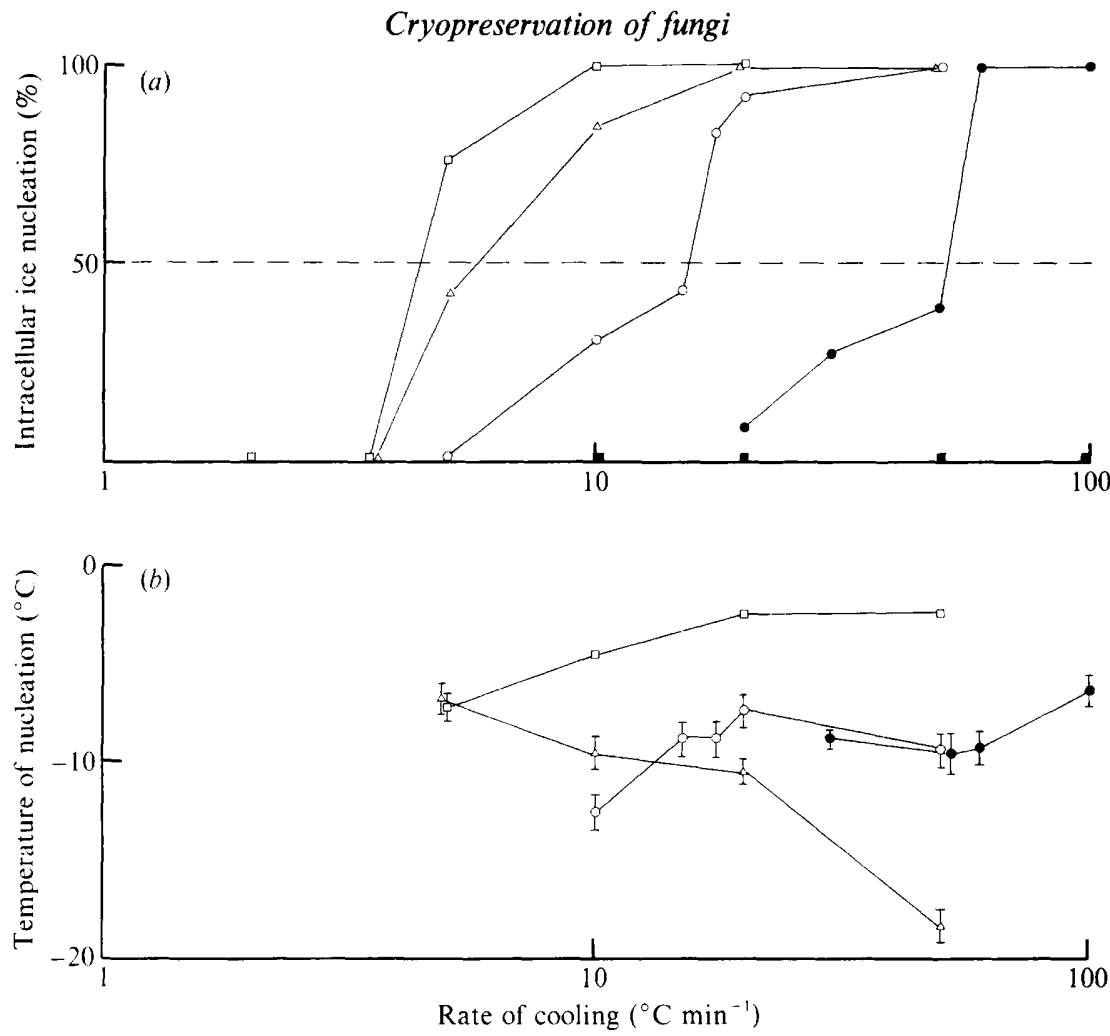

Fig. 2. (a) Percentage of intracellular ice formation within hyphae of Achlya ambisexualis $(\triangle)$, Phytophthora humicola (O), Saprolegnia parasitica $(\square)$, Serpula lacrymans $(O)$ and Volvariella volvacea (D). At least 25 hyphae from each species were observed at each rate of cooling. The dashed line indicates the rates of cooling at which $50 \%$ of the hyphae from these species formed intracellular ice. $(b)$ Temperature of intracellular ice formation within hyphae of Achlya ambisexualis $(\triangle)$, Phytophthora humicola $(O)$, Saprolegnia parasitica $(\square)$ and Serpula lacrymans $(O)$. The error bars show SE values when greater than $0.5^{\circ} \mathrm{C}$.

cooling was species-specific. In the hyphomycetes (Alternaria, Penicillium, Trichoderma, Trichophyton, Wallemia) and the ascomycete (Sordaria) the nucleation temperature was independent of the rate of cooling. However, in Pythium, Saprolegnia, Phytophthora humicola and the basidiomycete Serpula, the nucleation temperature for intracellular ice formation increased as the rate of cooling increased (Fig. 2, Table 2). The only exception to this was the species of Achlya (oomycete) where the nucleation temperature decreased with increasing cooling rate.

In the basidiomycete Serpula lacrymans, the age of the culture and the conditions of growth had a major effect on the response to freezing. With hyphae from a young culture $(7 \mathrm{~d})$ of this fungus, the cooling rate at which intracellular ice formed within $50 \%$ of hyphae was $15^{\circ} \mathrm{C}$ $\mathrm{min}^{-1}$. In an older culture (28 d) two distinct types of hyphae were present: in small hyphae $\left(<4.45 \mu \mathrm{m}\right.$ diameter) intracellular ice was not observed at cooling rates up to $100{ }^{\circ} \mathrm{C} \mathrm{min}{ }^{-1}$, but intracellular ice formed in larger hyphae with a critical rate of cooling of $1{ }^{\circ} \mathrm{C} \min ^{-1}$. In Mortierella elongata, the hyphae from liquid culture were uniform in appearance and behaviour during cooling. With hyphae from agar slopes there was a wide range of hyphal sizes, resulting in a bimodal response to cooling similar to that observed with Serpula lacrymans (see above).

\section{Effect of cryoprotectants on morphology during freezing}

The presence of glycerol modified the morphological response of hyphae of Penicillium expansum during freezing. The cooling rate required for intracellular ice formation increased with increasing glycerol concentration (Fig. 3). Observations of hyphae in the presence of glycerol concentrations greater than $2 \%$ were difficult at rates of cooling faster than $50{ }^{\circ} \mathrm{C} \mathrm{min}^{-1}$ 


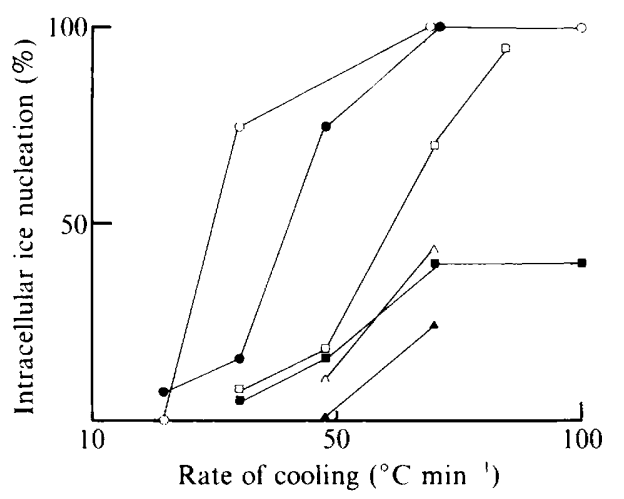

Fig. 3. Effect of different concentrations of glycerol on the intracellular nucleation of ice in Penicillium expansum. $\bigcirc$, Growth medium. Glycerol $(\%, v / v): 0,0.5 ; \square, 1 ; \square, 2 ; \triangle, 5 ; \Delta, 10$. At least 25 hyphae were observed at each rate of cooling.

Table 2. Critical cooling rates and ice nucleation temperatures of fungal hyphae in growth medium

$\begin{array}{ccc} & \begin{array}{c}\text { Critical } \\ \text { cooling } \\ \text { rate* }^{*} \\ \left({ }^{\circ} \mathrm{C} \min ^{-1}\right)\end{array} & \begin{array}{c}\text { Nucleation } \\ \text { temperature } \\ \left({ }^{\circ} \mathrm{C}\right)\end{array}\end{array}$

Mastigomycotina, Oomycetes

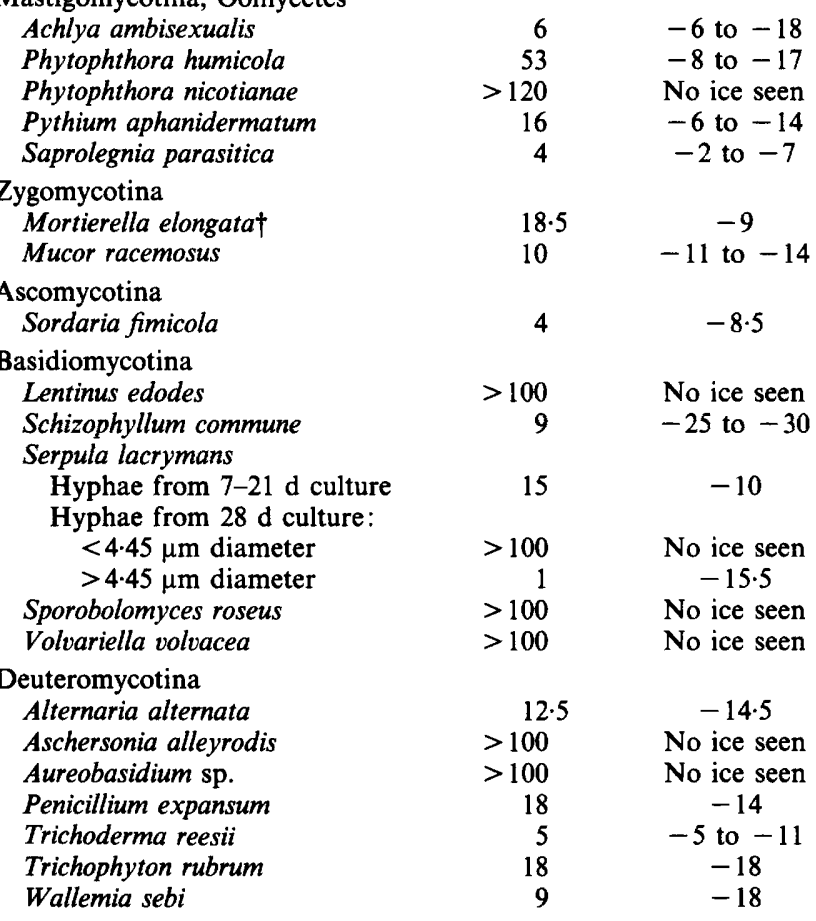

* The rate of cooling at which intracellular ice formed in $50 \%$ of the hyphae.

$\dagger$ The results presented here are those after growth in liquid medium.

as the pattern of extracellular ice formation in the presence of glycerol masked intracellular events. The presence of low concentrations (1-2\%) of other cryoprotectants (dimethylsulphoxide, proline and trehalose) led to intracellular ice formation only at faster rates of cooling. The nucleation temperature in the presence of low concentrations of glycerol $(<5 \%, v / v)$ was not significantly different from that in the presence of growth medium. 


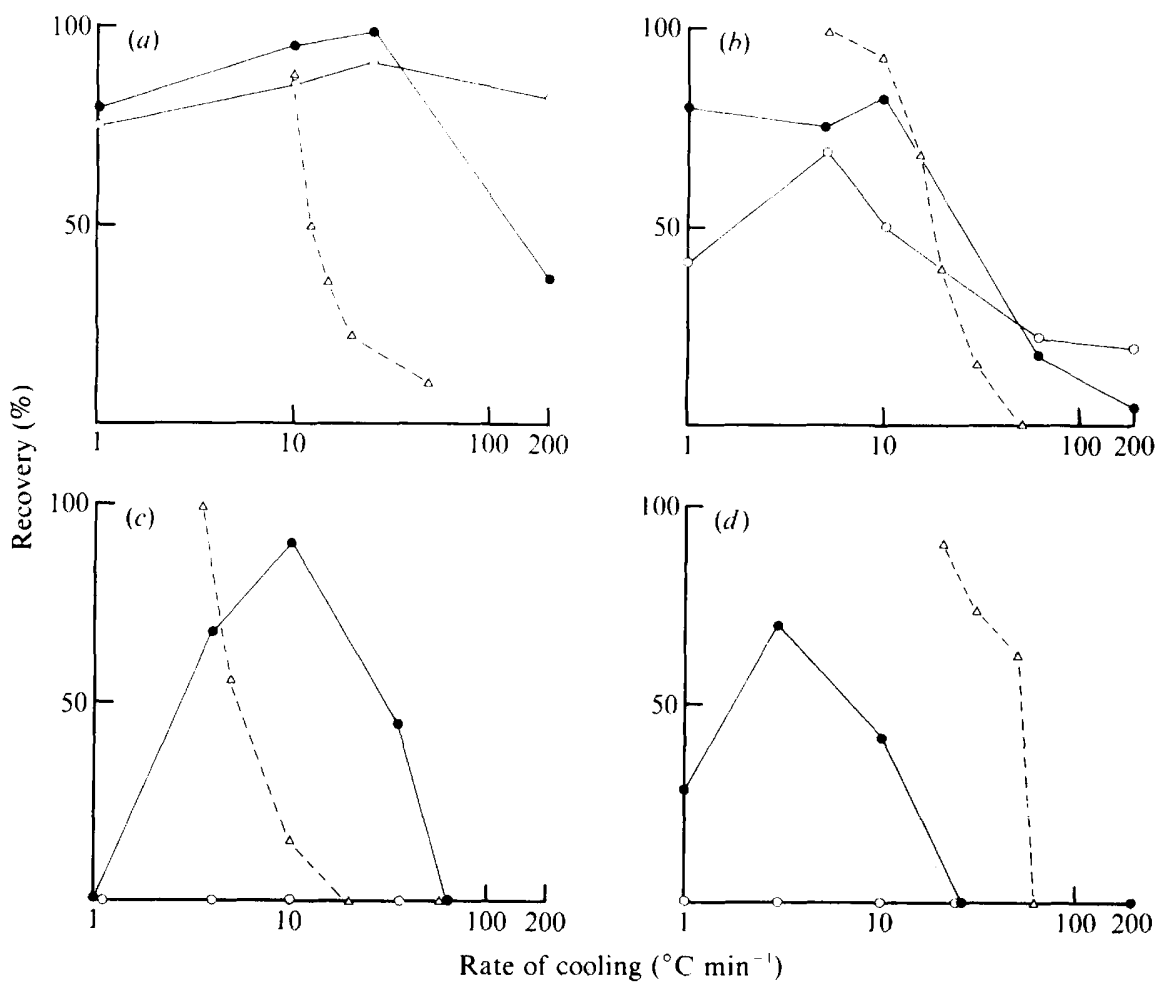

Fig. 4. Percentage recovery following cooling at different rates to $-196^{\circ} \mathrm{C}$ in either growth medium (O) or glycerol $(O)$ and intracellular ice formation $(\triangle)$ in hyphae of Alternaria alternata $(a)$, Trichophyton rubrum (b), Achlya ambisexualis (c) and Phytophthora humicola $(d)$.

\section{Viability following freezing and thawing}

The recovery obtained following freezing to and thawing from $-196{ }^{\circ} \mathrm{C}$ in the presence and absence of glycerol was dependent on the species (Fig. 4, Table 3). To examine the relationship between intracellular ice formation and loss of viability at rapid rates of cooling, the proportion of cells remaining free of intracellular ice is also presented in Fig. 4; this plot is the reciprocal of the data plotted in Fig. 2. Two patterns were observed: in some species recovery of hyphae was attained in the absence of cryoprotective additive and the maximum recovery attained was increased by the addition of glycerol; in the oomycetes and the basidiomycetes Serpula and Volvariella, recovery required glycerol. Recovery was also influenced by the rate of cooling; often a clearly defined optimum was observed (Table 3 ) with survival decreasing at both slower and faster rates (Table 3; Fig. 4).

\section{DISCUSSION}

The observations on the morphology of hyphae during freezing and thawing presented here extend earlier observations (Coulson et al., 1986; Smith et al., 1986). All hyphomycetes (Alternaria, Trichoderma, Trichophyton and Wallemia), zygomycetes (Mucor) and the ascomycete (Sordaria) examined responded in the manner previously reported for Penicillium expansum (Coulson et al., 1986), i.e. at slow rates of cooling there was sufficient time for osmotic shrinkage to occur whilst at faster rates of cooling hyphae became increasingly supercooled and intracellular ice formation occurred. Within the oomycetes (Achlya, Phytophthora, Pythium and Saprolegnia) and the basidiomycetes (Schizophyllum, Serpula and Volvariella) two types of 
Table 3. Optimum cooling rate and recovery of 20 species of fungi suspended in either growth medium or glycerol $(10 \%, v / v)$

Fungus

Mastigomycotina, Oomycetes Achlya ambisexualis Phytophthora humicola Phytophthora nicotianae Pythium aphanidermatum Saprolegnia parasitica

Zygomycotina Mortierella elongata* Mucor racemosus

Ascomycotina Sordaria fimicola

Basidiomycotina Lentinus edodes Schizophyllum commune Serpula lacrymans 7-21 d culture 28 d culture: $<4.5 \mu \mathrm{m}$ in diameter $>4.5 \mu \mathrm{m}$ in diameter Sporobolomyces roseus Volvariella volvacea

Deuteromycotina Alternaria alternata Aschersonia alleyrodis Aureobasidium sp. Penicillium expansum Trichoderma reesii Trichophyton rubrum Wallemia sebi

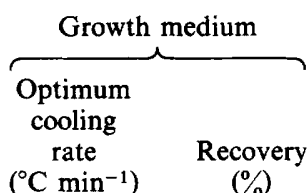

$(\%)$

\begin{tabular}{|c|c|}
\hline- & - \\
\hline- & - \\
\hline- & - \\
\hline- & - \\
\hline - & - \\
\hline $10-200$ & 95 \\
\hline 25 & 36 \\
\hline $1-200$ & $\approx 100$ \\
\hline 1 & 27 \\
\hline 1 & 92 \\
\hline - & - \\
\hline$\ldots$ & - \\
\hline- & - \\
\hline $4 \cdot 5$ & $\approx 70$ \\
\hline- & - \\
\hline $21 \cdot 5$ & 88 \\
\hline $10 \cdot 5$ & 86 \\
\hline $10 \cdot 2$ & 83 \\
\hline $0 \cdot 5-200$ & $85-100$ \\
\hline 3.8 & $\approx 100$ \\
\hline 4 & 70 \\
\hline 83 & $\approx 100$ \\
\hline
\end{tabular}

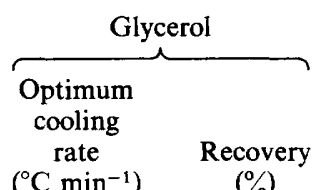

$(\%)$

$\begin{array}{cr}9 & 88 \\ 3 & 69 \\ 0 \cdot 5-11 & 72-91 \\ 8-29 & 52-53 \\ 10 & 32 \cdot 5 \\ & \\ 1-200 & 100 \\ 5 & 31\end{array}$

$1-200 \quad 100$

$1-3 \cdot 5 \quad 100$

$23 \quad 92$

$0.5 \quad 99$

$\begin{array}{cr}13 & 20 \\ 13 & 20 \\ 1 & \approx 100 \\ 1 & 38 \\ & \\ 20 & 97 \\ 1 & 100 \\ 200 & 91 \\ 1-12 & 75-90 \\ 3.8-10 & \approx 100 \\ 9 & 86 \\ 77 & \approx 100\end{array}$

* The results presented here are those after growth in liquid medium.

response were observed, dependent on the species, age of culture and growth conditions: the first was as reported for Penicillium (Coulson et al., 1986) and the second was shrinkage at all rates of cooling examined. The response of cells during freezing is determined largely by the water permeability of the cell, size, and the surface area to volume ratio. That the larger hyphae of basidiomycetes nucleate at lower rates of cooling than small hyphae is consistent with these general observations. With Phytophthora, shrinkage of large hyphae occurs at rapid rates of cooling, suggesting that these have a much higher degree of water permeability than other species examined.

In the hyphomycetes and the ascomycete examined, the temperature of intracellular nucleation was independent of the rate of cooling within the range studied. With many other cell types a similar response has been reported (McGrath et al., 1975; Morris \& McGrath, 1981; Dowgert \& Steponkus, 1983; Morris et al., 1986). With the other species of fungi examined intracellular nucleation temperature was a function of the rate of cooling; in most cases the nucleation temperature decreased at faster rates of cooling. However, in the oomycete Achlya the opposite relationship was observed, the nucleation temperature decreasing as the cooling rate increased. A dependence on cooling rate of the temperature of intracellular ice formation has also been reported for plant protoplasts (Steponkus \& Dowgert, 1983) and bovine oocytes (Meyers et al., 1987) when suspended in cryoprotectants. 
With the hyphomycetes, the zygomycetes, the ascomycete Sordaria and the basidiomycete Schizophyllum, high recovery was obtained in the absence of cryoprotective additives. From comparison with the cryomicroscopy it is apparent that hyphae of these species are resistant to both the stresses of extensive shrinkage and rehydration and the formation of intracellular ice. Such resistance is unusual but has been reported previously for Penicillium (Smith et al., 1986) and the unicellular green alga Chlorella protothecoides (Morris, 1976). Hyphae of the oomycetes and other basidiomycetes examined must be considered to be sensitive to such stresses.

In the presence of glycerol and other cryoprotective additives there was a shift in the rate of cooling at which intracellular ice was observed, to higher values. A similar shift has been reported for other cell types on the addition of a cryoprotectant and has generally been considered to be due to the alteration of the characteristics of water transport, direct effects on membranes, or increasing the amount of residual unfrozen fraction at any temperature (Leibo, 1977; Morris et al., 1986). However, we find it surprising that the addition of such low concentrations of glycerol has a major effect on intracellular ice formation.

The recovery following freezing to and thawing from $-196^{\circ} \mathrm{C}$ was increased by the addition of glycerol. This is generally assumed to be due to the reduction in concentration of ionic components during freezing. The recovery in the presence of glycerol was determined by the rate of cooling. In the hyphomycetes there was a reduction in viability at rapid rates of cooling compared to that observed in growth media, possibly due to osmotic stress imposed by the glycerol during freezing, a phenomenon described for other cells in cryoprotectant (Morris et al., 1986). In other species there was an optimum rate of cooling. The reduction in viability at supraoptimal cooling rates was in some cases related to the formation of intracellular ice (Fig. $2 c$ ). However, in Phytophthora humicola the reduction in viability at rapid rates of cooling occurred under conditions at which intracellular ice would not be expected to form (Fig. $4 d$ ); this is similar to the response previously reported for Phytophthora nicotianae (Smith et al., 1986).

The relationship for fungal hyphae between changes in morphology during freezing and subsequent viability is clearly not as simple as previously considered (Mazur, 1967) and requires further investigation. The findings of this study will facilitate the improvement of cryopreservation techniques for fungi. Strains belonging to the oomycetes have, in the past, failed to survive or shown low recovery after cooling at $1{ }^{\circ} \mathrm{C} \mathrm{min}-1$ (Smith \& Onions, 1983). These fungi will, however, survive if cooled at $10^{\circ} \mathrm{C} \mathrm{m^{-1 }}$ in $10 \%$ glycerol to $-40{ }^{\circ} \mathrm{C}$ followed by rapid cooling to $-196{ }^{\circ} \mathrm{C}$. The cooling of Serpula lacrymans at $0.5{ }^{\circ} \mathrm{C} \mathrm{min}-1$ (again in $10 \%$ glycerol) to $-40^{\circ} \mathrm{C}$ and rapid cooling to $-196^{\circ} \mathrm{C}$ has given much higher recoveries than $1{ }^{\circ} \mathrm{C}$ $\mathrm{min}^{-1}$ cooling. The optimum cooling rates for many of the fungi studied here were faster than the $1{ }^{\circ} \mathrm{C} \mathrm{min}-1$ previously recommended for the cryopreservation of fungi (Hwang, 1960; Smith \& Onions, 1983).

The authors wish to acknowledge the CEC Biotechnology Action Programme for sponsoring this study under contract 0028. $\mathrm{C}(\mathrm{H})$. Thanks also go to the collaborating laboratories, particularly CBS for supplying some of the strains examined and to Simon Ward and Tracy Mason for their technical assistance.

\section{REFERENCES}

Coulson, G. E., Morris, G. J. \& SMith, D. (1986). A cryomicroscopic study of Penicillium expansum hyphae during freezing and thawing. Journal of General Microbiology 132, 183-190.

Dowgert, M. F. \& STEPonkus, P. L. (1983). Effect of cold acclimation on intracellular ice formation in isolated protoplasts. Plant Physiology 72, 978-988.

HocH, H. C. (1986). Freeze-substitution of fungi. In Ultrastructure Techniques for Microorganisms, pp. 183-212. Edited by H. C. Aldrich \& W. J. Todd. New York \& London: Plenum Press.

HWANG, S. -W. (1960). Effects of ultralow temperature on the viability of selected fungus strains. Mycologia 52, 527-529.
LEIBO, S. P. (1977). Fundamental cryobiology of mouse ova and embryos. In The Freezing of Mammalian Embryos (Ciba Foundation Symposium 52, New Series), pp. 69-96. Edited by K. Elliot \& J. Whelan. Amsterdam: Elsevier.

MCGrath, J. J. (1987). Temperature controlled cryogenic light microscopy - an introduction to cryomicroscopy. In The Effects of Low Temperatures on Biological Systems, pp. 234-267. Edited by B. W. W. Grout \& G. J. Morris. London: Edward Arnold.

McGrath, J. J., Cravalho, E. G. \& Huggins, E. C. (1975). An experimental comparison of intracellular ice formation and freeze-thaw survival of $\mathrm{HeLa} \mathrm{S-3}$ cells. Cryobiology 12, 540-550. 
MazuR, P. (1967). Survival of fungi after freezing and desiccation. In The Fungi. III. The Fungal Population, pp. 325-394. Edited by G. C. Ainsworth and A. S. Sussman. New York \& London: Academic Press.

Meyers, S. P., Lin, T.-T., Pitt, R. E. \& Steponkus, P. L. (1987). Cryobehavior of immature bovine oocytes. Cryo-Letters 8, 260-275.

MORRIS, G. J. (1976). The cryopreservation of Chlorella. 1. Interactions of the rate of cooling, protective additive and warming rate. Archives of Microbiology $107,57-62$.

Morris, G. J., Coulson, G. E. \& ENGEls, M. (1986). A cryomicroscopic study of Cylindrocystis brebissonii de Bary and two species of Micrasterias Ralfs (Conjugatophyceae, Chlorophyta) during freezing and thawing. Journal of Experimental Botany 37, 842-856.
MoRRIS, G. J. \& MCGRath, J. J. (1981). Intracellular ice nucleation and gas bubble formation in Spirogyra. Cryo-Letters 2, 341-352.

Polge, C., Smith, A. U. \& Parkes, A. S. (1949). Revival of spermatozoa after dehydration at low temperatures. Nature, London 164, 666.

Smith, D. \& Onions, A. H. S. (1983). The Preservation and Maintenance of Living Fungi. Kew, UK: CAB International Mycological Institute.

SMITH, D., COulson, G. E. \& Morris, G. J. (1986). A comparative study of the morphology and viability of hyphae of Penicillium expansum and Phytophthora nicotianae during freezing and thawing. Journal of General Microbiology 132, 2013-2021.

STEPONKUS, P. L. \& DOWGERT, M. F. (1983). Influence of cold acclimation and suspending medium composition on the ice nucleation temperature of isolated protoplasts. Cryobiology 20, 735. 